\title{
Fergus Green*
}

\section{Legitimate Expectations, Legal Transitions, and Wide Reflective Equilibrium}

\author{
https://doi.org/10.1515/mopp-2016-0029
}

\begin{abstract}
Recent scholarly attention to 'legitimate expectations' and their role in legal transitions has yielded widely varying principles for distinguishing between legitimate and non-legitimate expectations. This article suggests that methodological reflection may facilitate substantive progress in the debate. Specifically, it proposes and defends the use of a wide reflective equilibrium methodology for constructing, justifying and critiquing theories of legitimate expectations and other kinds of normative theories about legal transitions. The methodology involves three levels of analysis - normative principles, their theoretical antecedents, and considered judgements about their implications in specific cases - and iteration between these three levels in an effort to ensure coherence. The payoffs from applying this methodology to the legitimate expectations debate are illustrated through a discussion of examples from the existing literature. Some proposed innovations to the methodology, including the incorporation of insights from the ideal/non-ideal theory debate, are likely to be of wider interest to political theorists.
\end{abstract}

Keywords: legitimate expectations, transitions, methodology, reflective equilibrium, non-ideal theory

\section{Introduction}

Changes in the law provide a fascinating domain in which to explore larger questions about the competing values of stability and change in human affairs. Theoretical attempts to reconcile normative tensions associated with the stable rule of law and the imperative to reform particular laws have varied widely. 'Legitimate expectations' approaches to legal transitions, which have multiplied in recent years, are emblematic of this wider variation. Sometimes, in order to move forward in a debate, it makes sense to step back. In that spirit, this article seeks to make progress on theorising about legitimate expectations, and legal

*Corresponding author: Fergus Green, Department of Government, London School of Economics and Political Science, Houghton Street, London WC2A 2AE, UK, E-mail: R.F.Green@lse.ac.uk 
transitions more generally, not by offering a new principle or theory, but by positing a methodology that promises to facilitate the construction, justification and critique of principles and theories in this domain.

The normative problem of legal transitions arises from an apparent tension between, on the one hand, the stability-related values promoted by the rule of law and, on the other, the reform-related values promoted by changing particular laws. A central justification for the rule of law is that it provides a stable set of rules on the basis of which agents can form expectations about the future and plan and execute projects accordingly (see Waldron 2016, section 6). The capacity agents have for long-term planning is, in turn, widely regarded as central to many conceptions of moral value, valuable agency, or the good life (e.g. Bratman 1987; Goodin 1995; Rawls 1999; Sidgwick 1962; Williams 1973). Moreover, many agents make long-term plans, and other 'durable' decisions (Shavell 2008, pp. $43 \mathrm{f}$.), on the basis of their expectations about the stability of the law. ${ }^{1}$ For example, they may buy an asset, learn a new skill, take a new job, or open a business based on an expectation that relevant provisions of their country's tax code will continue unchanged. When the law changes, those expectations may be frustrated and the supervening plan or project may consequently become less valuable; the person may experience a loss. ${ }^{2}$ Yet the rule of law doesn't mean rule by a static set of particular laws. Laws frequently do change. Moreover, we often think the law should change. That is, the reform of laws can also be instrumental to or reflective of other normative values - for example, it may enhance justice, improve aggregate 'goodness', or reflect legitimate democratic procedures that are intrinsically valuable. ${ }^{3}$ The problem of legal transitions is about how best to reconcile these competing values when laws change.

There are many potential normative 'solutions' to the problem of legal transitions. The topic has been approached from the normative-theoretic branches of at least three disciplines - politics, law, and economics - and from within numerous moral and political-theoretic traditions, including the

1 By laws I mean, for the purpose of this article, primary legislation enacted by the legislative branch of a government.

2 Others will also experience a gain, which itself raises interesting issues. I leave these to one side here, along with the question of how to best conceptualise the related concepts of 'loss', 'gain' and 'value'.

3 At this stage I am simply trying to motivate and frame the debate over legal transitions and legitimate expectations, so I am not committed to any particular conception of 'justice', 'goodness' or 'democracy', or any justification of such conceptions. All the reader needs to accept at this stage is that changing the law can, at least in some circumstances, itself be normatively desirable in some sense. 
utilitarian tradition (e.g. Kanbur 2003; Shaviro 2000), the classical liberal and libertarian tradition(s) (e.g. Bovens 2011; Epstein 1985), and liberal-egalitarianism (e. g. Brown 2012; Meyer and Sanklecha 2014).

One family of solutions invokes principles of legitimate expectations: normative principles that specify the conditions, if any, under which an agent's expectation of legal continuity is legitimate (Brown 2011; 2012; 2017; Buchanan 1975; Meyer and Sanklecha 2014; Rawls 1971). ${ }^{4}$ On this approach to the problem of legal transitions, the legitimacy of an agent's frustrated expectation of legal continuity is seen as a necessary - and perhaps sufficient - condition for the state's provision of some kind of transitional relief (e. g. compensation) to such 'losers'. ${ }^{5}$ Numerous principles have been proposed, which condition the legitimacy of an expectation on, variously: the justice of the expectation in question (or of the law on which it supervenes) (see Meyer and Sanklecha 2014, pp. $377 \mathrm{ff}$.); the justice of the basic structure (Rawls 1971, p. 10 and §48); the legitimacy of the state authority that makes the laws (Meyer and Sanklecha 2014, pp. $375 \mathrm{ff}$.); or the responsibility of state agents for inducing expectations of continuity (Brown 2017). ${ }^{6}$

Yet it is fair to say that legitimate expectations solutions to the problem of legal transitions are at an early stage of theoretical development. There is no consensus among proponents of existing principles, and the potential remains for other principles to be proposed. Accordingly, this subfield of political philosophy - along with the wider normative domain of legal transitions - would benefit from at least some agreement about a sound methodology for constructing, justifying and critiquing proposed principles.

The purpose of this article is to propose and defend such a methodology. The proposed methodology is a kind of wide reflective equilibrium (hereafter WRE). WRE was first proposed by Rawls (1971; 1974), ${ }^{7}$ systematically developed

4 I later refer to these as 'legitimacy principles' to distinguish them from other principles and concepts that a full theory of legitimate expectations arguably needs in order to be determinate (see Part 2, below).

5 Whether it is a necessary or sufficient condition is a question that a legitimate expectations theory of legal transitions would have to resolve. One could hold, for example, that an agent who has a frustrated legitimate expectation has (1) an all-things considered entitlement to transitional relief, (2) a pro tanto claim for transitional relief, or (3) a mere prima facie entitlement to transitional relief. Defending a particular theory is, however, not an aim of the present article.

6 Brown's principles apply to administrative policies and decisions, not to primary legislation. 7 Rawls uses the phrases 'wide' and 'narrow' reflective equilibrium in his article 'The Independence of Moral Theory' (1974, p. 8). Though he does not use these terms in A Theory of Justice, the distinction is there in substance (1999, p. 43). 
by Daniels (1996), and more recently defended by Knight (2006; 2017) among others. It is a coherentist methodology in the sense that it seeks coherence among normatively-relevant moral (and nonmoral) beliefs across at least three 'levels': a set of considered judgements about particular cases (the most specific level); a set of normative principles (the middle level); and a set of background theoretical elements (the most general level) (Daniels 1996, p. 22).

Drawing on this three-level account of WRE, ${ }^{8}$ and treating legitimate expectations principles as 'middle level' normative principles, this article argues that theorists should construct, justify and critique these normative principles with reference to a combination of desiderata at all three levels: 'internal' desiderata, concerning the formulation of the normative principles themselves (i. e. at the middle level); comparing considered judgements about particular (real or hypothetical) cases with the implications of applying the normative principles to those cases; and the relationship between the normative principles and more general theoretical antecedents. Metaphorically, we can move from the formulation of the normative principles 'downstream' to specific cases or 'upstream' to theoretical antecedents (cf. Sen 1979). By 'theoretical antecedents' I mean, loosely, any normative theories, normative principles, ideals, concepts, and nonmoral beliefs that play a significant role in the construction, justification or critique of middle level normative principles (cf. Daniels 1996, pp. $338 \mathrm{f}$.). ${ }^{9}$ Specific combinations of theoretical antecedents will often come pre-packaged in a tradition of political thought. Accordingly, I will often speak of traditions of political thought as shorthand for a package of theoretical antecedents that is more or less accepted among adherents to a particular tradition. Middle level normative principles are just that - normative principles ${ }^{10}-$ though they are

8 There can in principle be more than three levels of generality, and sometimes Daniels refers to more than three levels (e.g. 1996, pp. 23 f.). This article's main arguments can be substantiated with reference to only three levels, so in the interests of parsimony I limit my discussion to the three levels outlined here.

9 Daniels defines the 'theory' level as involving 'some or all of those elements involved in the process of giving a systematic account of moral beliefs and practices' (1996, p. 339). Daniels' definition, as well as his list of theoretical elements (1996, pp. 6, 338), and Knight's (2017, section 3) scheme of elements, are broader than mine in that they involve more elements than I have listed. I do not wish to preclude inclusion of such elements in WRE. Rather, I am merely focusing on normative, conceptual and nonmoral theoretical elements because these are the focus of my article, and they are sufficient to advance my claims about the benefits of using WRE in the context of debates about legitimate expectations and legal transitions.

10 Strictly speaking, the object of analysis at the middle level could also be a normative theory, where a theory is understood as a set of normative principles (along with auxiliary assumptions) and the statements it implies that plays some prescriptive role (List and Valentini 2016, pp. 536 f.). However, to avoid confusion between the middle level and the more general level, 
distinguished by having a more specific domain of application than their theoretical antecedents (Daniels 1996, pp. $22 \mathrm{ff} .$, ch. 3). ${ }^{11} \mathrm{I}$ take it that the notion of considered judgements ${ }^{12}$ about particular cases, and implicational methods more generally, are sufficiently self-explanatory for now (see List and Valentini 2016, pp. 540 ff.; Sen 1979).

The argument is developed as follows. Part 2 elaborates on the three levels individually, and argues that analysis at each level adds value to the task of constructing, justifying and critiquing middle level normative principles. It also highlights some limitations of each kind of analysis when used in isolation from the other levels. Part 3 discusses how WRE, involving moving back and forth across all three levels to ensure coherence between them, adds further methodological value by helping to overcome some of the limitations discussed in Part 2. Throughout, the argument will be substantiated by critical engagement with legitimate expectations principles. In this way, I hope to show directly that using this version of WRE can yield progress on the topic of legitimate expectations, and in the wider domain of legal transitions. It is also hoped that the innovations to WRE discussed throughout will be of more general methodological interest to political theorists.

\section{Three levels of analysis: Expanding the constructive, justificatory and critical scope}

This part introduces the three levels in more detail and explains how analysis at each level provides distinctive avenues for theory construction, justification and critique.

One could start at any level: for example, one could be implications-oriented, focusing on reaching considered judgements about particular cases, or theoretically-oriented, starting with the ideals of a particular political-philosophical

consisting of 'theoretical antecedents', I will typically refer to the unit of analysis at the middle level as 'principles' (as does Daniels 1996) but, in the interests of clarity in certain passages, I will sometimes refer to the middle level as involving normative 'principles/theories'.

11 In this way, what counts as a middle level normative principle is defined relatively to its theoretical antecedents.

12 I adopt Knight's (2017) definition of considered judgements, which refers to Rawls' requirement that the judgements are those made in 'conditions favorable for deliberation and judgment in general' (Rawls 1999, p. 42). According to Knight (2017, Section 2), this is all that is required for a judgement to be deemed 'considered' and thus admitted into the reflective equilibrium process. 
tradition. It would be difficult to start theory construction de novo at the middle level, i.e. without any theoretical antecedents or considered judgements about cases in mind. However, I begin the discussion below at the middle level because, by stipulation, the focus of that level is the set of normative principles (or the normative theory ${ }^{13}$ ) that is the primary object of our inquiry - in our case, legitimate expectations principles/theories in the context of legal transitions.

\subsection{The middle level: normative principles/theories}

Without considering the more general theoretical antecedents of a middle level principle/theory, or its implications when combined with specific factual information pertaining to a particular context, we only have 'internal' criteria against which to evaluate it, i. e. criteria pertaining to the internal structure of the principle/theory formulation itself (List and Valentini 2016, p. 539). Various mostly formal - internal criteria have been posited (see especially List and Valentini 2016, pp. 539 f.; Timmons 2002, pp. 13 f.). ${ }^{14}$

I will focus on the criterion of determinacy, as this is the most insightful internal criterion for exploring the benefits of the proposed methodology. A determinate theory will contain the elements necessary, when combined with specific factual information, to yield definite verdicts about the subject matter being evaluated (Timmons 2002, pp. $13 \mathrm{f}$.). ${ }^{15}$

For example, to be determinate with respect to a wide range of cases of legal transitions, a theory of legitimate expectations must arguably include the following elements:

1. A specification of the kinds of agents that have 'moral standing' to make claims for transitional relief or incur transitional obligations (e. g. presumably this will include natural persons, but what about corporations and other group agents?);

13 See footnote 10, above.

14 The internal criteria posited by List and Valentini (2016, pp. 539f.) are 'consistency', 'deductive closure', 'axiomatizability' and 'parsimony'. I will not elaborate on these here. Timmons' (2002, pp. 13f.) internal criteria, like List and Valentini's, include 'consistency', but additionally 'determinacy'. Timmons' work pertains to moral theory but the evaluative criteria he posits are just as relevant to political theory.

15 Note that the specification of the determinacy criterion makes it sound like an implicational criterion, and in practice a principle/theory may need to be tested by considering a wide range of particular cases in order for us to know how determinate it is. However, the criterion is in fact internal, since the focus is ultimately on whether the principle/theory formulation itself has the elements necessary to yield definite verdicts in a wide range of particular cases, rather than on the evaluation of its substantive implications in specific cases. 
2. A conception of the relevant transitional effects in respect of which agents could in principle make claims for transitional relief or incur transitional obligations (e.g. which conception of 'loss' and 'gain' should apply?);

3. A specification of the available responses to a transitional claim/obligation (e. g. compensation, grandfathering, ${ }^{16}$ forward-looking adaptation assistance, etc.);

4. A set of principles that determines when a recognised agent who has experienced a recognised effect is entitled to a recognised transitional response (including a principle specifying the conditions under which an agent has a legitimate expectation of legal continuity - what I shall call a legitimacy principle), and to which kind of transitional response they have a claim.

Understandably, the legitimate expectations literature has focused on legitimacy principles - that part of the fourth element where most of the normative controversy is located (Brown 2011; 2012; 2017; Meyer and Sanklecha 2014). All of the legitimacy principles that have been discussed in the literature (see part 1) are moralised in that they include references to concepts such as 'justice', 'legitimate authority', or 'responsibility'. A specification of each of these controversial normative concepts is thus required in order to render the associated legitimacy principle reasonably determinate (as these authors are keenly aware).

This need to specify normative concepts illustrates a limitation of considering the internal criterion of determinacy in isolation: it would be difficult to specify a satisfactory conception of such concepts (or to critique such conceptions) without recourse to theoretical antecedents such as the dominant conceptions of these concepts/ideals in a political tradition, or to considerations of the implications of importing alternative conceptions into the moralised middle level principles/theory. The process of identifying and resolving indeterminacy is therefore greatly assisted by a process of WRE, as discussed in part 3.

Of the four elements listed above, elements 1, 2 and 3 are also, strictly speaking, necessary to render a legitimate expectations theory determinate. These elements are less commonly discussed in the literature (an exception is Brown 2011 who discusses elements 2 and 3). Yet, without them, a theory of legitimate expectations would not yield definite verdicts in many cases. Without, for example, knowing whether the theory applies to corporations, the theory

16 'Grandfathering' provisions in laws are provisions that exempt from the application of the law those persons who had made durable decisions under the law that previously applied to the relevant situation, in effect ensuring that it is the previous law that governs their behaviour, not the new one, at least to such an extent and/or until such time as is specified in the grandfathering provision. 
would be indeterminate in a wide range of important transitional cases, since many of the most financially valuable durable decisions in the contemporary economy are business investments made by corporations. Moreover, corporations frequently make arguments of a transitional nature when lobbying against proposed legal reforms and at the same time make claims on governments for transitional relief in the event a reform is enacted. To theorise about legitimate expectations without considering the moral standing of corporations is to ignore one of the most normatively controversial and politically important sets of issues at the heart of legal transitions. This point will be further underscored in part 3 in the course of discussing the example of corporations and climate change legislation. It is therefore notable that even Meyer and Sanklecha (2011; 2014), who explicitly focus on the case of climate change, are silent on this question, meaning their proposed principles are indeterminate with respect to cases involving corporations.

I do not wish to suggest that every contribution to the theoretical debate about legitimate expectations must always include all of the above-mentioned elements. Of course, the debate can be advanced though contributions addressing particular elements of, or justifications for, a theory of legitimate expectations. Whether a critic's 'indeterminacy critique' of a proponent's contribution is fair or illuminating depends on what the proponent is purporting to do in their contribution. If they are purporting to advance a full theory, then the critic's charges of indeterminacy are fair and may be illuminating. If the proponent is purporting to make merely a partial contribution, as will often be the case, then an indeterminacy critique may or may not be fair or illuminating; the critic has to make a professional judgement.

The above example of Meyer and Sanklecha's omission to discuss the standing of corporations to make transitional claims is perhaps a borderline case. On the one hand, Meyer and Sanklecha are quite reasonably focusing on the legitimacy principle alone, and it would be obviously unfair to critique their contribution because it, say, failed to consider in detail the relevant conception of 'loss' or 'harm' that a theory of legitimate expectations should use. ${ }^{17}$ However, the indeterminacy charge with respect to the standing of corporations is not so obviously unfair, and is, I think, at least illuminating. As I will suggest in part 3, whether or not corporations have moral standing to make transitional claims makes a large difference to our intuitions and considered judgements about the implications of legitimacy principles in important cases, and also raises important background theoretical issues. A legitimacy principle that has intuitively appealing implications, and appears theoretically sound, when considering cases involving natural

17 Indeed, they explicitly leave this to one side (2014, p. 389, notes 2 and 3). 
persons, might turn out to be intuitively unappealing and theoretically dubious when considering cases involving corporations. Thus the question of corporations' moral standing bears heavily on the justification, and hence critique, of the very legitimacy principles that Meyer and Sanklecha discuss.

The more general point is that considering internal criteria such as determinacy provides a useful prompt for theory construction and justification, and opens a potential avenue of critique. Ultimately, however, constructing good middle level principles/theories clearly requires recourse to normative and empirical information beyond the principle/theory formulation itself, hence I now turn to consider theoretical antecedents, followed by case-specific implications.

\subsection{The more general level: theoretical antecedents}

In this section, I will explain the general methodological benefits that can be gained by appealing to more general theoretical phenomena - particularly the ideals, concepts, theories and nonmoral beliefs that constitute core features of a political tradition - in the construction, justification and evaluation of middle level normative principles.

There is, I think, a certain scepticism common in much contemporary political philosophy about the invocation of such theoretical antecedents in the course of domain-specific theorising about middle level principles. Let me respond to this at the outset, in the hope that this will allay any misgivings readers may have and clarify the reasons why this level of analysis is important.

One reason for such scepticism may be an assumption that any appeal to theoretical antecedents involves foundationalism. Foundationalism in political theory is the method of attempting to construct or justify a normative theory by reference to a non-moral and non-political foundation that itself does not require normative justification (Ripstein 1987). Indeed, there may well be good reasons to reject foundationalism, so understood, in political theorising (Ripstein 1987). But the appeal to theoretical antecedents that I have in mind in this section is not foundationalist in this sense: theoretical antecedents are simply more general, less domain-specific, and less context-dependent theoretical phenomena than middle level principles, but they too are open to contestation and revision. Nor is WRE (discussed in part 3) foundationalist in this sense: all objects included in the process of WRE are in principle subject to critical scrutiny and revision (Daniels 2016, section 1). ${ }^{18}$

18 See Knight (2006, pp. $216 \mathrm{ff}$.) for a discussion of whether the role of considered judgements in WRE makes the approach foundationalist, and if so in what sense. 
A related reason for scepticism may be the identification of such 'upstream' theorising with appeals to a comprehensive moral point of view, such as utilitarianism or Kantianism. For example, List and Valentini (2016), when referring to the one upstream method that they consider in their discussion of 'external criteria' for evaluating normative theories, discuss the 'applied moral philosophy method'. This involves constructing, justifying or evaluating a theory on the basis that it 'can be derived from some independently accepted moral principles or theory' (2016, p. 543). But the method I am discussing invokes a wider range of (contestable and revisable) upstream theoretical phenomena. As Daniels has noted: 'The diverse appeals to theoretical considerations we need to make in solving problems should not be confused with the adoption of some particular comprehensive moral view; some may accept such views, but most people have much more eclectic and diverse conceptions of theory' (1996, p. 350).

A third possible reason for ignoring theoretical antecedents when analysing middle level principles is that proponents of such principles may be making a tactical move, seeking to convince interlocutors of principles that may be compatible with a wide range of more general theoretical antecedents. This is a perfectly reasonable tactic as far as it goes. However, I suspect it doesn't go as far as one might hope. Theory is, surely, always there, lurking in the background (Daniels 1996, p. 337). And the background work that more general theoretical elements are doing may well often be philosophically significant and interesting. First, proponents of a middle level principle will often need to appeal to theoretical antecedents in order to specify or interpret concepts (e.g. liberty, legitimacy) contained in the principle formulation if the principle is to be sufficiently determinate to yield definite verdicts in a wide range of cases. Second, they may need to appeal to theoretical antecedents as premises in justifications for those principles. I develop these claims further below, when discussing the 'constitutive' and 'justificatory' roles of theoretical antecedents.

A fourth possible concern is that invoking theoretical antecedents will open a veritable Pandora's Box of considerations that are not worth spending time and effort addressing in the course of analysing the middle level principles at hand. But this worry disappears once we appeal to the practical norms of professional philosophy, which dictate that we only raise matters that are philosophically interesting in the context at hand. Moreover, in part 3, I will explain a more specific method for fastening critiques based on theoretical antecedents to the middle level principles under scrutiny, which should further dispel this concern.

I will now develop my claim about the methodological benefits of appealing to theoretical antecedents, with reference to the domain of legal transitions. Recent theorising about legitimate expectations appears to reflect some of the 
conventional caution about appealing to political-theoretical antecedents (but see Brown 2012). This is striking because the normative problem of legal transitions is about the roles, claims and responsibilities of persons/citizens (and corporations, perhaps) and the state, with respect to changing the laws by which a polity is governed; it is fundamentally a highly political issue. Theories of legitimate expectations therefore rest inevitably on a set of political-theoretic antecedent commitments, including conceptions of: the person (and of any other relevant agents, such as corporations) and of what is valuable to those persons/agents (and hence what transitional effects are normatively salient); the state; and the institution of citizenship (being the institutional bond between person and state) - or at least conceptions of those features of each that are relevant to legal transitions. It is instructive to consider some of these theoretical elements that are implicit or explicit in normative theoretical work on legal transitions and legitimate expectations in order to shed light on the general methodological value of analysing them when constructing, justifying and critiquing middle level normative principles.

Let me make this a little more concrete by sketching (in a necessarily oversimplified and cursory way) the two dominant liberal conceptions of the person as examples of the kind of theoretical antecedents to which I am referring, which I will then draw on for illustration in the subsequent discussion of legitimate expectations principles. There are two key features of liberal conceptions of persons that I wish to emphasise - which we might call the ontological feature and the contextual feature.

First, liberals broadly share a commitment to an individualist ontology and tend to assume individuals have a strong capacity for autonomous rational reflection and choice. From this shared ontological starting point, the liberal tradition refracts into two dominant ideal types (Willett et al., 2015, section 1): the homo economicus of the classical liberal tradition, who uses instrumental rationality to rank his internally-generated desires or preferences and who goes about maximally satisfying these; and the autonomous planner of the liberalegalitarian tradition, who is capable of rationally constructing, revising and pursuing a conception of the good according to which he lives his life. Though these two ideal-types have been, in some cases, moderated in the course of debate with critics, ${ }^{19}$ it is fair to say that contemporary liberals commonly identify persons' individual capacity for relatively free/independent choice as being a normatively important feature of persons (e. g. Kymlicka 1989).

19 As in, for example, the infamous liberal-communitarian debates about the nature of the self (for an overview, see Bell 2016, section 2). 
The way in which individuals' capacity for free choice takes on normative importance, however, depends on the spheres of life in which individuals are imagined as legitimately exercising choices. This takes us to the contextual feature of conceptions of the person - and here the two dominant liberal traditions part ways (with implications for the kind of legitimacy principles one might want to construct, as we shall see shortly). In the classical liberal tradition, the marketplace takes on special significance as a private sphere in which productive activity creates the goods and services that satisfy individuals' desires/preferences. Accordingly, classical liberals emphasise the importance of economic rights and freedoms of property ownership, contract and trade (see Freeman 2007, p. 45); in some versions of classical liberalism, these are seen as the embodiment of liberty (Gaus et al. 2015, section 2.1). Accordingly, classical liberals were eager to preserve this zone of freedom from interference by the state, hence the strict separation between the public sphere and the private sphere of the market (and the household).

Further, in the classical liberal imaginary, the affordances and demands of modern economic life left citizens with neither interest in nor time for public political deliberation (Constant 1819). Correspondingly, the institution of citizenship in the classical liberal tradition serves as a legal protection for civically passive individuals from interference by the state so that they may pursue their private good relatively uninterrupted (Leydet 2015, section 1.2). In this way the special normative status of the classical liberal person's desires/preferences manifests itself differently with respect to two distinct spheres of life: in a logic of personal responsibility for managing risks in the marketplace; and in a logic of protection in the public sphere, wherein a person's desires/preferences are shielded from state interference, such protection being appropriate for a sphere in which the individual outsources responsibility to representatives and is imagined as taking no interest (Constant 1819). This contextual aspect of the classical liberal conception of the self, argues Taylor (1989, part III), is bound up with modernity's 'affirmation of ordinary life' - the life of productive work and family - and its rejection of life goods such as philosophical contemplation and civic virtue that were exalted in earlier periods.

The liberal-egalitarian tradition maintains a concern for ordinary life but is more concerned with the political-institutional context necessary for individuals to form, revise and rationally pursue their conceptions of the good life. Liberalegalitarians therefore tend to prioritise political liberties over economic ones in securing those capacities (Freeman 2007; Gaus et al. 2015; Rawls 1993) and to emphasise the state's primary function in securing and maintaining 'the conditions for realising [the liberal-egalitarian] ideal of persons' (Freeman 2007, p. 51). We might anticipate, therefore, that liberal-egalitarians would expect more of 
individuals qua citizens (who have the Rawlsian powers of rationality and reason) with respect to participation in processes of legal change, apprehension of legal changes, and critical reflection on the legal status quo. Rawls' brief remarks concerning the natural duty to establish just arrangements (albeit without 'too much cost' to oneself) suggest an inclination along these lines to bridge the gap between private life and civic duty in non-ideal societies (Rawls 1999, p. 99).

We are now in a position to see why a classical liberal would probably construct a very different legitimate expectations theory of legal transitions than would a liberal-egalitarian. For example, a classical liberal would likely posit a legitimacy principle that offers individuals strong protections against the risk of losses caused by legal transitions (i. e. a conservative principle), even though they would counsel laissez faire in the marketplace generally. The individual's desires and preferences are, in the classical liberal imaginary, legitimately subject to disruption in the marketplace, where foresight and good judgement must be cultivated to avoid losses and efficiently allocate resources. But since individuals are imagined as legitimately disengaged from public political life, one cannot reasonably expect them to exercise the same degree of foresight and judgement about legal changes. All or most expectations of legal continuity would appear, in this light, legitimate. Accordingly, the losses caused by such legal changes would likely give rise to a claim for transitional relief (which would likely take the form of pecuniary compensation). This hypothesis is broadly confirmed by existing classical liberal and libertarian writings on legal transitions (e.g. Bovens 2011; Epstein 1985). ${ }^{20}$ Moreover, given the strong emphasis on freedoms of economic production in the classical liberal tradition, classical liberals may well be inclined to grant business corporations moral standing to press claims for transitional assistance and to grant them the same protections as natural persons (e. g. as Bovens 2011 appears to do).

By contrast, it would be possible for a liberal-egalitarian to construct a legitimacy principle that holds individuals responsible for bearing the outcomes of their durable decisions that are affected by legal changes in some cases, but not in others. Concerned to respect the long-term life plans of autonomous individuals, liberal-egalitarians are also more likely to be concerned ultimately about transitional effects that undercut persons' autonomy, and so disrespect them, rather than with economic losses per se (Brown 2011; 2012; Buchanan 1975). Liberalegalitarians, with their emphasis on personal planning and politically-secure autonomy, arguably also possess the conceptual resources to justify awarding

20 These do not use the rubric of 'legitimate expectations', but are effectively grappling with the same normative problem (see part 4, below). 
transitional relief to corporations in a narrower set of cases than classical liberals, or even a null set, though this would require further argumentation.

In light of this discussion, we can posit a number of general ways in which the consideration of theoretical antecedents, especially when packaged in a political tradition, can improve the construction, justification and critique of middle level normative principles.

First, political traditions can motivate and frame the very problem that is the object of the middle level theorising. From the above example, we can see how classical liberals, in light of their widely shared political ideals and conceptualisations of relevant agents and institutions, might more readily perceive legal transitions to be a problem in the first place. A republican political theorist, on the other hand, might have a harder time seeing legal transitions per se as problematic, or at least might frame the issue in a different way. The motivation for considering a political problem, and the framing thereof, are manifestly important to the construction of any normative theory to address that problem.

Second, a political tradition can supply conceptions of ideals and of other important concepts that are deployed in the relevant middle level principles (a constitutive function ${ }^{21}$ ), or that are invoked (e.g. as premises) in justifications of the middle level principles (a justificatory function). As we have seen, liberalegalitarians and classical liberals conceptualise persons, the state and citizenship in distinctive ways. Such conceptualisations (in any political tradition) will inevitably also draw on nonmoral beliefs and assumptions, for example about the nature of persons and moral psychology (Daniels 1996, pp. 6, 13, ch. 7). These traditions also emphasise certain ideals, such as liberty and autonomy, and adopt distinctive conceptions of those ideals that cohere with their conceptualisation of agents and institutions. All of these theoretical elements inevitably inform their theorising about middle level principles.

Legitimate expectations theorists writing within these traditions do indeed tend to invoke such ideals and concepts for constitutive and/or justificatory purposes. For example, Meyer and Sanklecha, in their discussion of the "normative authority' legitimacy principle (2014, pp. $375 \mathrm{ff}$; see also 2011, pp. $453 \mathrm{ff}$., $467 \mathrm{f}$.), consider the following candidate legitimacy principle: an expectation (of legal continuity) will be legitimate if the state/authority itself is legitimate. They go on to say that the 'intuitive plausibility' of that legitimacy principle lies in the special role played by the state in the formation of people's expectations of legal continuity:

21 I don't mean to suggest these would be completely constitutive, i. e. they will tend to be partly constitutive, in the sense that they feature in the specification of the middle level principles/theory. 


\begin{abstract}
The state does this through the operation of its coercive mechanisms, and the question of legitimate authority is essentially the question of the conditions under which such coercion is justified. The intuitive idea, therefore, is that if that coercion is justified, then the citizens of that state are correspondingly justified in forming expectations based on the legitimate actions of the state. (2014, p. 375, footnote removed)
\end{abstract}

Thus, the legitimacy of an expectation of legal continuity is conditioned on the legitimacy of the state that makes the laws, and the issue of state legitimacy is discussed in terms of liberal debates about the legitimate exercise of coercive power over citizens (see also Meyer and Sanklecha 2011, pp. $454 \mathrm{ff}$.). Both the conceptualisation and the justification of legitimacy are thickly informed by antecedent commitments in liberal political theory.

Third, a political tradition itself may adhere to certain core, general principles. For example, liberals take liberty to be normatively basic, meaning state intervention must be justified, and paradigmatic liberals take the set of justifiable state interventions to be relatively small (Gaus et al. 2015, section 1.1). Egalitarians take human beings to be 'morally equal' in some relevant sense (Carter 2011). Any middle level principle that purports to sit within a political tradition should therefore be at least consistent with any such core principles. In this way, the core principles constrain the set of possible middle level principles that govern more specific domains. A good example of this is Brown's (2011) Rawlsian justification for a principle of administrative law that would honour legitimate expectations created by administrative decisionmakers. To qualify as a Rawlsian justification, Brown argues, the principle must cohere with the 'Kantian roots' of justice as fairness, and thus must respect persons by treating them not as mere means but as ends in themselves (2011, pp. 721, $724 \mathrm{f}$.).

Fourth, the concepts, ideals and core principles of a political tradition, where they explicitly or implicitly feature in some middle level principle, or in a justification thereof, can be the legitimate object of a critique of the middle level principle. Insofar as a political tradition supplies the conception of a concept used in a middle level principle (e. g. liberty, legitimate authority), a critique of that conception straightforwardly entails a critique of that middle level principle. Insofar as a political tradition supplies the premise of a justification for the middle level principle, a successful critique of the relevant elements of the political tradition reduces the support available for the middle level principle (see also List and Valentini 2016, p. 546). Consider the examples just discussed concerning liberal conceptions of the person and their implicit role in justifying associated legitimacy principles. Exposing those controversial liberal theoretical antecedents and their role in a legitimacy principle renders the legitimacy principle vulnerable to criticisms not only from competing 
strands of liberalism, but also from republicanism and from critical schools such as feminism, Marxism, communitarianism and conservativism (see, e. g., Ramsay 1997).

Broadly, two relevant types of theoretical critique can be envisaged, one general and one specific. A general theoretical critique focuses exclusively on the more general theoretical elements that play a constitutive or justificatory role in a particular middle level principle, and treats any blows struck against these elements as applying by extension to the middle level principle (i. e. in our case, a legitimacy principle or wider theory of legitimate expectations). One limitation of this method, however, is that the criticism of general political theories per se is, of course, a much bigger subject; there is a risk that the critical analysis becomes insufficiently tethered to the primary object of criticism, viz. the middle level principle.

However, a second, more specific kind of theoretical critique can be envisaged: one which focuses not on the elements of a political tradition at large, but rather on theoretical idealisations and the constitutive or justificatory role they play in the relevant middle level principle. This kind of theoretical critique has the virtue of being more tightly fastened to the middle level principle. Operationalising this narrower kind of theoretical critique, however, requires iteration between all three levels of analysis, therefore it will be taken up in Part 3.

For now, it suffices to understand the four ways just discussed in which analysis of theoretical antecedents on its own expands the avenues available for the construction, justification and critique of middle level principles relative to using only internal and/or implicational methods.

\subsection{The more specific level: implications and considered judgements}

The third level of analysis relevant to the construction, justification and critique of middle level principles is their application to specific (hypothetical or real) cases. As noted in the earlier discussion of determinacy, such application should imply a definite verdict about the deontic status of the state of affairs in that case, or should imply appropriately clear guidance about what ought to be done in that case (as applicable). Testing middle level principles in a range of cases and comparing the implications with relevant intuitions or considered judgements, ${ }^{22}$ as in Rawlsian 'narrow reflective equilibrium' (NRE) (Rawls 1974, p. 8; 1999, pp. $41 \mathrm{ff}$; Daniels 2016, section 3.1), is of course a

22 As to what, and whose, the 'relevant judgements' are, see List and Valentini (2016, pp. $542 \mathrm{f}$.). 
well-established and widely-used method for constructing (or refining), justifying and critiquing middle level principles (List and Valentini 2016, p. 542; Timmons 2002, p. 15).

For example, in a case involving a legal transition, a set of middle level legitimate expectations principles should yield definite or at least appropriately action-guiding conclusions about who (if anyone) has a normatively valid claim to transitional assistance, and to what kind of assistance they have a claim. The implications of the principles in that case may cohere with our considered judgements, in which case this provides some justificatory support for the theory, ${ }^{23}$ or they may not, in which case this may assist the proponent of those principles to refine them (thus its constructive function) or may simply count against the unrefined principles (thus its critical function) (List and Valentini 2016, p. 542). ${ }^{24}$

Interestingly, despite the wide use of implicational methods in political theory generally, relatively little use of such methods has yet been made by legitimate expectations theorists studying legal transitions. ${ }^{25}$ This is particularly striking since laws change frequently, meaning there is a rich repertory of available real-world cases against which to test the implications of legitimate expectations theories/principles. Accordingly, I suggest that greater use of implicational methods would assist future theorising in this domain.

Since I take it to be uncontroversial that implicational methods generally, and NRE specifically, can add methodological value (relative to using only internal and/or 'upstream' theoretical methods), I will not discuss them much further here. I will simply highlight various controversies and limitations associated with NRE as a method of theory construction/critique (for an overview, see Daniels 2016, section 3; List and Valentini 2016, pp. $541 \mathrm{ff}$.) as a precursor to demonstrating in part 3 how WRE can help to mitigate some such concerns. ${ }^{26}$

23 Or at least, it is widely taken to provide such support. The method, of course, has its critics (see, e. g., Daniels 2016, Section 4).

24 I say 'may' with regard to cases of dis-equilibrium because we always have, in such cases, the alternative option of revising out considered judgements while leaving the principles intact. 25 One exception is Brown (2011; 2012; 2017), who discusses a range of actual examples, including legal cases, from the field of administrative decisions, but this work does not address legislative changes, which are the focus of my discussion concerning legitimate expectations theories. Another exception is Meyer and Sanklecha (2014) who consider the case of climate change mitigation laws, but they consider only that case.

26 In addition to the controversies and criticisms of reflective equilibrium considered here, the method has been criticised for its use of intuitions or considered judgements. These criticisms have been responded to in detail (and to my mind, convincingly) elsewhere (Daniels 1996, pp. 3 ff., 29 ff.; Knight 2006, pp. 220 ff.), so I leave these aside here. 
The main limitation of NRE is that it leaves unanswered the question of why we should accept certain principles. A NRE generates a 'fit' between our considered judgements and a set of normative principles, but this is more akin to a descriptive account - a kind of moral anthropology or moral grammar - than a normative account of justification (Daniels 2016, section 3.1). To use Timmons' terminology, narrow reflective equilibria lack 'explanatory power'; they lack an ability to explain the underlying features of the object of normative evaluation that make it right/wrong, good/bad etc. (2002, pp. $15 \mathrm{f}$.). I will argue in Part 3 that WRE overcomes this limitation.

Another controversy concerns whose considered judgements should count in the process of reflective equilibrium (List and Valentini 2016, pp. 542f.). For example, should we use the theorist's judgements (which will inevitably be influenced by her own theoretical/ideological commitments or worldview) or the judgements of a society (which might be more 'democratic', but are likely to be affected systematically by the structural/social forces dominant in that society)? Other challenges pertain to the potential non-uniqueness and pathdependence of particular equilibria (see List and Valentini 2016, p. 542). There is no entirely satisfactory way to overcome these challenges. However, I will suggest in Part 3 that the recourse to political-theoretical antecedents allowed by WRE can at least mitigate these concerns.

\section{Wide reflective equilibrium}

We have now discussed, with particular reference to legitimate expectations principles, how middle level normative principles can be constructed, justified and critiqued using: (i) 'internal' criteria, in particular 'determinacy'; (ii) theoretical antecedents; and (iii) implicational methods such as NRE. We also saw how analysis at each of these levels in isolation has its limitations. I now discuss how considerations across these three levels can be linked through a kind of WRE and how doing so can help to mitigate some of these limitations, thus yielding further methodological improvements (see also Daniels 1996, ch. 16). The payoff will again be illustrated with reference to legitimate expectations theories of legal transitions.

Let us assume first that we wish to start our theory construction, justification or critique at the most general theoretical level, e. g. with the ideals, conceptions and (if applicable) core general principles of a particular tradition of political thought. In part 2, I identified a limitation with this approach - namely that theoretical critiques 'at large' may be insufficiently tethered to the middle level principles under scrutiny - and foreshadowed that having recourse to the other 
two levels facilitates a second kind of theoretical analysis that is more closely tied to the middle level principles. This second kind of analysis I have in mind draws on the notion of an 'idealisation' - defined as a simplifying or limiting falsehood about some matter that plays some role in a political theory (O'Neill 1987; 1996, pp. $41 \mathrm{ff}$.) - and on recent discussion of the (in)appropriate uses of idealisation in political theory (List and Valentini 2016, pp. $544 \mathrm{ff}$; Valentini 2009). Below, I show how these insights can be integrated into earlier work on WRE (Daniels 1996) to develop a methodological technique that yields payoffs for theorising about legitimate expectations.

Critics of 'ideal theory' as a method or orientation in political theory have noted the extent to which ideal theorising relies on idealisations (e. g. Farrelly 2007; Mills 2000; O’Neill 1987; 1996, ch. 2). Yet it has also been argued that idealisations are not necessarily undesirable (Valentini 2009). Indeed, some degree of idealisation in a theory is almost inevitable, and 'may play an important, and justified, heuristic role' (List and Valentini 2016, p. 545). In order to distinguish acceptable from unacceptable idealisations, scholars have argued that we must: (a) consider the particular role that an idealisation plays with respect to the principle/theory under scrutiny; and (b) assess the suitability of that role in light of the principle/theory's purpose (List and Valentini 2016, pp. $544 \mathrm{ff}$; Robeyns 2008; Valentini 2009). With respect to (a), List and Valentini (2016, pp. $545 \mathrm{ff}$.) propose that we need to distinguish between three possible loci at which idealisations can occur: the theory/principle formulation itself; the conditions of application of the theory/principle's prescriptions; and the justification of the theory/principle. ${ }^{27}$ With respect to (b), scholarly discussion has focused on the fact that a widely shared purpose of political theorising is to develop theories that are to some extent 'action-guiding in the sense of offering a framework of thought from within which to assess, criticize and reform the way power is exercised within society' (Valentini 2009, p. 337). ${ }^{28}$ Accordingly, idealisations can be assessed by reference to how they affect the performance of the theory with respect to guiding real-world action. And this in all but the most trivially obvious examples - is something that can only be

27 List and Valentini label these loci as levels (1), (2) and (3) - I have jettisoned these labels here to avoid confusion between these and my own three-level scheme, which serves a different but overlapping analytical purpose. List and Valentini also refer to 'theories' when discussing this point; I have referred to 'theories/principles' to clarify that the point applies equally to both (see footnote 10, above).

28 Some - so-called 'fact-insensitive' - political theories do not purport to be action-guiding (see Valentini 2009, pp. $334 \mathrm{ff}$. for discussion). I leave these to one side as my discussion applies only to 'fact-sensitive' political theories. 
determined by applying the relevant theory/principle to specific cases and engaging in 'sustained argumentation' (Valentini 2009, p. 355).

This proposed approach to idealisations maps readily onto my proposed three-level methodology, and the process of WRE more generally. First, political traditions tend to be rich fonts of idealisation, as we saw earlier when discussing liberal conceptions of the person, citizen and state that explicitly or implicitly figure in legitimate expectations theories. Indeed, this 'tendency to theorise "in the ideal" is one of the hallmarks of contemporary liberal egalitarianism' (Valentini 2009, p. 334), and the same can surely be said about other strands of liberalism. I suggest that much of what is potentially interesting about the constitutive or justificatory role played by political traditions in middle level principles is, or can readily be expressed in terms of, their dominant idealisations of political phenomena (agents, institutions, etc.). The process of explicitly identifying the political-theoretic antecedents of middle level principles, then, can serve to illuminate idealisations. Second, List and Valentini's three potential loci of idealisation readily reduce to what I called (in part 2) the constitutive and justificatory functions of political-theoretic antecedents: idealisations in 'the theory itself' and in the 'conditions of application' of the theory's prescriptions are essentially what I have called constitutive functions ${ }^{29}$; and the justificatory function is common to both our schemes. Accordingly, we can usefully trace idealisations from political traditions through to the role they play in the middle level principle under scrutiny. Third, when we apply the middle level principle to particular cases and compare its implications with our considered judgements, we can assess the appropriateness of the idealisation by considering how it affects the principle's action-guiding qualities. Where the idealisation, middle level principle and considered judgements about specific cases are coherent, we will be in a state of WRE with respect to all of these elements.

Let me now illustrate the value of this approach using the example of legitimate expectations theories that incorporate idealised conceptions of agents, particularly business corporations.

Within the domain of scholarship on legal transitions, some theories/principles are strongly protective of the interests of the 'losers' from legal change call these 'conservative' theories for simplicity. Such theories/principles include the 'normative authority' legitimacy principle discussed by Meyer and Sanklecha (2014, pp. $375 \mathrm{ff} ., 387)^{30}$ and, outside of the legitimate expectations literature,

29 Indeed, these two loci are so similar that in Valentini's (2009) article they are not distinguished. 30 For an alternative interpretation of Meyer and Sanklecha's normative authority legitimacy principle, see Brown (2017). I am grateful to Alex Brown for discussion of this interpretive issue, on which we reasonably disagree. 
pure Paretian theories (see Kanbur 2003), theories inspired by the classical liberal and libertarian tradition (e.g. Bovens 2011), and 'old view' theories in law and economics (discussed in Shaviro 2000, pp. $2 \mathrm{f}$.). Were corporations to enjoy such protections - as is typically envisaged in these theories, except the normative authority legitimacy principle (Meyer and Sanklecha are silent on this matter, as noted earlier) - the consequences for resource claims on the state would be extremely large in the case of a great many legal reforms, including those that are widely considered necessary or highly desirable from the standpoint of enhancing justice or goodness. ${ }^{31}$

Consider, for example, the case of laws enacting policies to mitigate climate change. The vast majority of global greenhouse gas emissions have been caused by a relatively small number of privately-owned and state-owned corporations. ${ }^{32}$ Achieving the internationally-agreed objective of restraining global warming to less than $2^{\circ} \mathrm{C}$, with a two-thirds probability, requires reducing emissions to netzero by around the last quarter of this century (IPCC 2014, fig. SPM.4), therefore emissions from presently-emitting companies will need to be phased out entirely or almost entirely, which will require extensive policy and legal changes (Stern 2015). The combined asset value of fossil fuel companies is estimated at around US\$5 trillion (Bullard 2014). Accordingly, any conservative theory of legal transitions that applies to corporations would imply that the likes of Exxon Mobil, Shell, Chevron and BP have a normative claim on the state for trillions of dollars in compensation for economic losses caused by climate change mitigation laws such as carbon taxes and fossil fuel supply quotas - laws that are necessary to mitigate large-scale harms and risks of civilisational-scale catastrophes. ${ }^{33}$

I submit that this implication of such theories is objectionable. Assuming that the necessary climate change laws were to be enacted and the compensation were to be paid, this seems like, at best, a phenomenal waste of society's

31 See footnote 3, above.

32 Heede (2014) found that between 1894 and 2010, two-thirds of greenhouse gas emissions from fossil fuels and cement production were caused by just 90 companies (50 private/investorowned, 31 state-owned, and 9 nation-state producers).

33 The Carbon Tracker Initiative (2011) estimates that the fossil fuel reserves held by the top 100 stock exchange-listed coal companies and the top 100 listed oil and gas companies represent potential emissions of $745 \mathrm{GtCO}_{2}$ (and this figure ignores those resources held by unlisted state entities), which exceeds the remaining global $2{ }^{\circ} \mathrm{C}$ 'carbon budget' (the amount of $\mathrm{CO}_{2}$ that can be emitted whilst staying within the internationally agreed objective of limiting global warming to within $2{ }^{\circ} \mathrm{C}$ above pre-industrial levels) by $180 \mathrm{GtCO}_{2}$. This means that using just the listed proportion of remaining fossil fuel reserves in the next 40 years would be enough to take the world beyond $2^{\circ} \mathrm{C}$ of warming, which is widely regarded by experts as entailing significant risks of catastrophic outcomes. 
economic resources that could be put to better use and, at worst, an endorsement of gross past injustice on the part of many of these companies. Indeed, I take these implications to be a reductio ad absurdum of those theories. Similar implications that I take to be repugnant would follow from the application of such conservative theories to corporations in the context of new financial regulation, economic inequality-reducing income and wealth taxation, improved labour standards, more stringent environmental regulation and taxation, and more.

However, beyond inviting readers to share my considered judgements, what could I do to improve the force of this criticism? This is where it can be helpful to trace the role that idealisations in political traditions play in the middle level principles.

In the kinds of cases under consideration, idealisations of agents such as corporations play a justificatory role $\mathrm{e}^{34}$ : one might attempt to justify a corporation-inclusive conservative theory, in spite of the implications just considered, by appealing to an analogy with the classical liberal conception of persons. ${ }^{35}$ Such an attempt might go something like this: persons enhance their welfare through private consumption, and have neither time nor inclination to engage in politics; institutional arrangements and the dominant ethos in contemporary market-liberal societies do not foster capacities for normative reflection on existing laws or public-spirited engagement in law reform; rather the institution of citizenship merely protects persons from interference by the state; it is therefore legitimate that citizens expect laws, once made, to continue; therefore compensation should be paid when the enactment of a new law frustrates their expectation of legal continuity and causes economic (and hence welfare/ utility) loss. This analogical approach would effectively give the idealisation of corporations a justificatory role with respect to corporation-inclusive conservative theories of legal transitions.

But this justification is eminently susceptible to critique in virtue of the idealisation on which it relies. Whatever the empirical merits of the above conception of natural persons, the same logic clearly does not apply to corporations: contemporary corporations, at least reasonably large ones, are not politically passive, private welfare-maximisers, but politically active profitmaximisers who seek through various channels systematically to influence the

34 The idealisation does not play a constitutive role because the theory would apply to all corporate agents, not only to 'idealised' ones - as compared with certain theories that apply to idealised agents: see Valentini (2009, pp. $347 \mathrm{ff}$.) on the distinction and its significance.

35 I am not suggesting that a classical liberal would necessarily endorse the analogical extension to corporations, though I suspect many probably would. 
content of laws in their interests (Crouch 2011). In a world of Super-PACs, lobbying firms, and corporate in-house government affairs departments, the idea that corporations are purely private planners that can legitimately expect the law to remain the same is fanciful. Thus we have identified an idealisation that seriously weakens the relevant justification because it is 'too idealized to allow inferences for the real world' (List and Valentini 2016, p. 546). We can be more confident that it is too idealised because when we apply it to cases like climate change law reform, we see how a background idealisation can lead to implications that many would consider to be problematic.

This illustrates a more general point made by O’Neill (1996, pp. 41ff.) and Valentini (2009, pp. $351 \mathrm{ff}$.) concerning idealisations: theories that idealise the very agents/subjects that 'the theory itself aims to put under moral scrutiny' are highly vulnerable to the critique that the theories are insufficiently action-guiding (Valentini 2009, p. 352). This is because a theory that applies only to idealised agents will not apply to agents in the real-world (O’Neill 1996, pp. $41 \mathrm{ff}$.; Valentini 2009, pp. $351 \mathrm{ff}$.). That point applies to idealisations that play what I have called a constitutive role in middle level principles/theories (see also Robeyns 2008). But a similar point can be made about idealisations of agents that play a justificatory role: a justification that appeals to agents with idealised capabilities and interests will fail to provide justificatory support for principles insofar as they apply to agents that do not have the idealised capabilities or interests (O'Neill 1996, p. 41; cf. List and Valentini 2016, p. 546). Whether the discrepancy between idealisation and reality is significant in a particular domain will require close examination. In the domain of legal transitions, as I have argued, the discrepancy is large and extremely consequential, as the case of corporations and climate change law starkly illustrates. Indeed, given the important role of considerations of agency (plans, projects, expectations, etc.) in the justification of theories of legal transition - especially in legitimate expectations theories - theorists working in this domain should be particularly wary of idealisations of agents when constructing, justifying and critiquing such theories.

More generally, we can see how tracing idealisations in background political traditions through their role in middle level normative principles, and onto the implications of those principles in specific cases, yields a methodological improvement over merely considering 'at large' critiques of political traditions: it provides a justification/critique that is more closely tethered to the middle level principles under examination. While I have focused on the methodological payoffs that consideration of theoretical antecedents in WRE yields for work on middle level principles, the above discussion also demonstrates how this approach can yield progress in debates about theoretical antecedents themselves, particularly the elements of political traditions (see 
also Daniels 1996, chs. 9, 10). For example, it helps us to distinguish between 'good' and 'bad' dominant idealisations in political traditions, which is theoretically valuable in itself.

The above example also illustrates how the kind of WRE advocated here improves upon NRE. We identified in part 2 some limitations of the latter concerning its lack of explanatory power, the need to ascertain whose judgements count, and the risk of non-unique and path-dependent equilibria. Broadening the objects of reflective equilibrium to include theoretical antecedents (including idealisations), as in WRE, offers a means of mitigating these problems. The main advantage of WRE is that broadening the scope of critical reflection to include more general theoretical elements increases our ability to explain the underlying theoretical features of principles and judgements that make them right/wrong, good/bad (Daniels 1996, pp. $24 \mathrm{f} ., 28,32$ ); it increases the 'explanatory power' of our normative principles/theories (Timmons 2002, pp. $15 \mathrm{f}$.). We saw this above in the discussion of corporation-inclusive conservative legitimacy principles: by illuminating the role of idealisation in the purported justification of middle level principles, we were able to explain why the implications are troubling, and thus to provide a deeper theoretical critique of those principles than merely appealing to considered judgements. Conversely, a proponent of such a legitimacy principle is confronted with a more theoretically troubling criticism than the criticism that such a principle does not fit with 'our' considered judgements about certain cases: s/he is forced to reflect on the appropriate conceptualisation of corporations and their relationship to the lawmaking process in contemporary society.

A related methodological point is that there is more likely to be convergence among beliefs about more general theoretical matters (e. g. how to conceptualise agents), and agreement on such matters can be leveraged to reduce disagreement about middle level principles and case-specific judgements (Cohen 1989; Daniels 1996, pp. 6 ff., 25 f., 32). The greater explanatory power and leveraging of agreement on more general questions afforded by WRE could help to arbitrate between non-unique equilibria and also render equilibria more robust to framing effects, mitigating the risk of 'path-dependence'.

These benefits of using WRE also reduce the significance of the 'which judgements matter' problem. Ultimately, the more compelling, not to mention practical, view is that it is the theorist's judgements (or, more generally, those of the person doing the reflection) that matter (Rawls 1999, p. 44; Daniels 1996; Knight 2006, pp. $213 \mathrm{ff}$.). But broadening the scope of reflective equilibrium to include theoretical antecedents helps to expose our own political-ideological predispositions, including any idealisations lurking there, and prompts us either to reaffirm or to reconsider these in light of the novel context in which, via middle 
level principles, they are being applied (Daniels 1996, pp. 5 f., 62; Rawls 1999, p. 43). It also prompts us to search more deeply for biases relating to our own experience and social position. Expanding our own experience and taking account of the considered judgements of other people, especially those whose social experience and position differ from our own, is a helpful, perhaps necessary incident of the theoretical rigour demanded by WRE (DePaul 1987; 1993; Knight 2006, pp. $213 \mathrm{ff}$.). While the limitations of reflective equilibrium are unlikely to be avoidable entirely, using WRE at least holds out the prospect that they will be mitigated (Daniels 1996, pp. 6 ff.; Rawls 1999, p. 43; Knight 2006).

Finally, recall from part 2.1 that we identified a limitation in our ability to analyse determinacy without recourse to theoretical antecedents and judgements about particular cases. WRE straightforwardly overcomes this limitation by providing additional theoretical resources with which to specify concepts used in the middle level theory/principle formulation (i. e. as per the 'constitutive function' of theoretical antecedents - see part 2.2), and by enabling the testing of middle level principles in a wide range of cases.

In sum, at whichever level we begin the task of constructing, justifying or critiquing middle level principles/theories such as legitimate expectations principles, by using the kind of WRE advocated here we will mitigate the limitations of using one (or two) levels of analysis alone, thus yielding further methodological improvements.

\section{Conclusion}

This article has proposed a methodology for constructing, justifying and critiquing theories/principles of legitimate expectations in legal transitions. The methodology involves three interdependent levels of analysis: the middle level normative theory/principle itself (and internal criteria for evaluating it); its theoretical antecedents; and considered judgements about the implications of the theory/principle when applied to particular cases. A good middle level theory/principle, I suggested, will be determinate in a wide range of relevant cases in the domain of application (and will meet other, more formal, internal criteria), will rely on defensible theoretical antecedents (including only 'acceptable' idealisations), and will have implications that align with our considered judgements in a wide range of cases. Part 2 argued that each level adds methodological value relative to considering only one or two of the others alone, but also has limitations when considered in isolation from the other levels. Part 3 showed how these limitations can be overcome by moving back and forth between the three levels in a kind of WRE: drawing the line between 
acceptable and unacceptable idealisations can be non-arbitrarily done by tracing idealisations through principles and onto their implications; the explanatory power of our considered judgements about implications can be enhanced by appealing to theoretical antecedents; and we can leverage agreement on more fundamental matters to forge agreement on more domain-specific sources of disagreement. Throughout the discussion, the payoffs from using this methodology were illustrated by considering examples from the growing literature on legitimate expectations theories of legal transitions.

Let me conclude with an observation about the legitimate expectations literature that the methodology employed here has helped to illuminate. As noted in the introduction, yet seemingly unbeknown to scholars of legitimate expectations, normative scholarship on legal transitions has been and is being undertaken in the normative sub-disciplines of economics, ${ }^{36}$ law (including 'law \& economics' ${ }^{37}$ ), and elsewhere in political philosophy. ${ }^{38}$ Collectively, this body of work contains an array of middle level principles concerning transitions - i. e. similar to my fourth required element of legitimate expectations theories (see part 2.1) - albeit using different conceptual devices, such as efficiency, utility or rights, rather than legitimate expectations. Theoretical antecedents (e.g. conceptions of persons/citizens, the state, moral value and loss) from a given tradition of political thought often inform multiple middle level theories that use entirely different conceptual devices from one another. It is arguably these theoretical antecedents that end up doing much of the normative work that is typically attributed to the conceptual devices deployed in middle level principles. Accordingly, principles that have common political antecedents will tend to have similar implications when applied to the same cases of legal transitions. In light of this tendency, there is a case for merging the discussions. Much would likely be gained, theoretically and practically, from subsuming the debates about 'theories of legitimate expectations in legal transitions' into a wider normative debate about 'normative theories of legal transitions', with a stronger emphasis on more general points of convergence and divergence in their theoretical antecedents. ${ }^{39}$

It is hoped that the methodology discussed here will prompt this kind of intellectual advance in the field of legal transitions, and facilitate progress in other domains of normative political theory.

36 See, e. g., Kanbur (2003) and works there cited.

37 See, e. g., Shaviro (2000) and the works discussed in Wonnell (2003).

38 See, e. g., Bovens (2011), Fried (2003) and Goodin (1995).

39 This project is the subject of work in progress by the author. 
Acknowledgements: I am grateful to Eric Brandstedt, Kai Spiekermann, Joe Mazor, two anonymous reviewers and the guest editors of the present special issue for helpful comments. An earlier version of this article was presented at the conference on Justice and Legitimate Expectations, held in Graz during June 2016, at which I benefited from discussions with the conference participants, among whom I wish especially to thank Sabine Hohl, who formally responded to my presentation, and Alex Brown.

\section{References}

Bell, D. (2016). 'Communitarianism', The Stanford Encyclopedia of Philosophy, https://plato. stanford.edu/entries/communitarianism/ (accessed on August 16, 2017).

Bovens, L. (2011). 'A Lockean Defense of Grandfathering Emission Rights', in D.G. Arnold (ed.). The Ethics of Global Climate Change (Cambridge: Cambridge University Press), pp. 124144.

Bratman, M.E. (1987). Intention, Plans and Practical Reason (Cambridge, MA.: Harvard University Press).

Brown, A. (2011). 'Justifying Compensation for Frustrated Legitimate Expectations', Law and Philosophy 30 (6): 699-728.

Brown, A. (2012). 'Rawls, Buchanan, and the Legal Doctrine of Legitimate Expectations', Social Theory and Practice 38 (4): 617-645.

Brown, A. (2017). 'A Theory of Legitimate Expectations'. Journal of Political Philosophy. doi:10.1111/jopp.12135

Buchanan, A. (1975). 'Distributive Justice and Legitimate Expectations', Philosophical Studies 28: 419-425.

Bullard, N. (2014). Fossil Fuel Divestment: $A$ \$5 Trillion Challenge (Bloomberg New Energy Finance White Paper). https://data.bloomberglp.com/bnef/sites/4/2014/08/BNEF_DOC_ 2014-08-25-Fossil-Fuel-Divestment.pdf (accessed on September 15, 2017).

Carbon Tracker Initiative. (2011). Unburnable Carbon - are the World's Financial Markets Carrying a Carbon Bubble? (Carbon Tracker Initiative). https://www.carbontracker.org/wpcontent/uploads/2014/09/Unburnable-Carbon-Full-rev2-1.pdf (accessed on September 15, 2017).

Carter, I. (2011). 'Respect and the Basis of Equality', Ethics 121 (3): 538-571.

Cohen, J. (1989). 'Democratic Equality', Ethics 99 (4): 727-751.

Constant, B. (1819). 'The Liberty of the Ancients Compared with that of the Moderns', available at: http://www.earlymoderntexts.com/assets/pdfs/constant1819.pdf (accessed on August 16, 2017).

Crouch, C. (2011). The Strange Non-Death of Neo-Liberalism (Cambridge: Polity Press).

Daniels, N. (1996). Justice and Justification: Reflective Equilibrium in Theory and Practice (Cambridge: Cambridge University Press).

Daniels, N. (2016). 'Reflective Equilibrium', The Stanford Encyclopedia of Philosophy, https:// stanford.library.sydney.edu.au/entries/reflective-equilibrium/ (accessed on August 16, 2017).

DePaul, M.R. (1987). 'Two Conceptions of Coherence Methods in Ethics', Mind 96: 463-481. 
DePaul, M.R. (1993). Balance and Refinement: Beyond Coherence Methods of Moral Enquiry (London: Routledge).

Epstein, R.A. (1985). Takings: Private Property and the Power of Eminent Domain (Cambridge, MA.: Harvard University Press).

Farrelly, C. (2007). 'lustice in Ideal Theory: A Refutation', Political Studies 55 (4): 844-864. Freeman, S. (2007). Rawls (London: Routledge).

Fried, B.H. (2003). 'Ex Ante/Ex Post', Journal of Contemporary Legal Issues 13: 123-160.

Gaus, G., Courtland, S.D., and Schmidtz, D. (2015). 'Liberalism', The Stanford Encyclopedia of Philosophy, http://stanford.library.sydney.edu.au/entries/liberalism/ (accessed on August 16, 2017).

Goodin, R.E. (1995). Utilitarianism as a Public Philosophy (Cambridge: Cambridge University Press).

Heede, R. (2014). 'Tracing Anthropogenic Carbon Dioxide and Methane Emissions to Fossil Fuel and Cement Producers, 1854-2010', Climatic Change 122 (1-2): 229-241.

IPCC. (2014). 'Summary for Policymakers', in O. Edenhofer, et al (eds.). Climate Change 2014: Mitigation of Climate Change. Contribution of Working Group III to the Fifth Assessment Report of the Intergovernmental Panel on Climate Change (Cambridge: Cambridge University Press), pp. 1-30.

Kanbur, R. (2003). 'Development Economics and the Compensation Principle', International Social Science Journal 55 (175): 27-35.

Knight, C. (2006). 'The Method of Reflective Equilibrium: Wide, Radical, Fallible, Plausible', Philosophical Papers 35 (2): 205-229.

Knight, C. (2017). 'Reflective Equilibrium', in A. Blau (ed.). Methods in Analytical Political Theory (Cambridge: Cambridge University Press), pp. 46-64.

Kymlicka, W. (1989). Liberalism, Community and Culture (Oxford: Clarendon Press).

Leydet, D. (2015). 'Citizenship', The Stanford Encyclopedia of Philosophy, http://stanford. library.usyd.edu.au/entries/citizenship/ (accessed on August 16, 2017).

List, C. and Valentini, L. (2016). 'The Methodology of Political Theory', in H. Cappelen, T. Szabó Gendler and J. Hawthorne (eds.). The Oxford Handbook of Philosophical Methodology (Oxford: Oxford University Press), pp. 525-550.

Meyer, L. and Sanklecha, P. (2011). 'Individual Expectations and Climate Justice', Analyse \& Kritik 33 (2): 449-471.

Meyer, L. and Sanklecha, P. (2014). 'How Legitimate Expectations Matter in Climate Justice', Politics, Philosophy \& Economics 13 (4): 369-393.

Mills, C.W. (2000). “'Ideal Theory” as Ideology”, Hypatia 20 (3): 165-184.

O'Neill, O. (1987). 'Abstraction, Idealization and Ideology in Ethics', Royal Institute of Philosophy Supplement 22: 55-69.

O'Neill, O. (1996). Towards Justice and Virtue: A Constructive Account of Practical Reasoning (Cambridge: Cambridge University Press).

Ramsay, M. (1997). What's Wrong with Liberalism? A Radical Critique of Liberal Political Philosophy (London: Leicester University Press).

Rawls, J. (1971). A Theory of Justice (Cambridge, MA.: Harvard University Press).

Rawls, J. (1974). 'The Independence of Moral Theory', Proceedings and Addresses of the American Philosophical Association 48: 5-22.

Rawls, J. (1993). Political Liberalism (New York: Columbia University Press).

Rawls, J. (1999). A Theory of Justice: Revised edition (Cambridge, MA.: Harvard University Press). 
Ripstein, A. (1987). ‘Foundationalism in Political Theory', Philosophy \& Public Affairs 16 (2): $115-137$.

Robeyns, I. (2008). 'Ideal Theory in Theory and Practice', Social Theory and Practice 34 (3): 341-362.

Sen, A. (1979). ‘Equality of What?', The Tanner Lecture on Human Values (Stanford University) 22 May. http://tannerlectures.utah.edu/_documents/a-to-z/s/sen80.pdf (accessed on September 15, 2017).

Shavell, S. (2008). 'On Optimal Legal Change, Past Behavior, and Grandfathering', The Journal of Legal Studies 37 (1): 37-85.

Shaviro, D. (2000). When Rules Change: An Economic and Political Analysis of Transition Relief and Retroactivity (Chicago: University of Chicago Press).

Sidgwick, H. (1962). The Methods of Ethics: Seventh edition (London: MacMillan \& Co).

Stern, N. (2015). Why are We Waiting? the Logic, Urgency, and Promise of Tackling Climate Change (Cambridge, MA.: The MIT Press).

Taylor, C. (1989). Sources of the Self: The Making of the Modern Identity (Cambridge: Cambridge University Press).

Timmons, M. (2002). Moral Theory: An Introduction: First edition (Maryland: Rowman \& Littlefield).

Valentini, L. (2009). 'On the Apparent Paradox of Ideal Theory', Journal of Political Philosophy 17 (3): 332-355.

Waldron, J. (2016). 'The Rule of Law', The Stanford Encyclopedia of Philosophy, https://stan ford.library.sydney.edu.au/entries/rule-of-law/ (accessed on August 16, 2017).

Willett, C., Anderson, E., and Meyers, D. (2015). 'Feminist Perspectives on the Self', The Stanford Encyclopedia of Philosophy, http://plato.stanford.edu/entries/feminism-self/ (accessed on August 16, 2017).

Williams, B. (1973). 'A Critique of Utilitarianism', in J.J.C. Smart and B. Williams (eds.). Utilitarianism For \& Against (Cambridge: Cambridge University Press), pp. 80-150.

Wonnell, C.T. (2003). 'The Noncompensation Thesis and Its Critics: A Review of This Symposium's Challenges to the Argument for Not Compensating Victims of Legal Transitions', Journal of Contemporary Legal Issues 13: 293-311. 